\title{
Paulo Freire e os modelos de formação docente: a práxis como categoria
}

\section{Paulo Freire and the models of teaching training: praxis as a category}

\author{
Caio Corrêa Derossi ${ }^{1}$ \\ Bethânia Medeiros Geremias²
}

\begin{abstract}
Resumo
Neste ensaio realizamos uma pesquisa de natureza bibliográfica com o intuito de analisar e compreender os contributos de Paulo Freire para o campo de pesquisas em formação de professores, refletindo sobre as interfaces de suas teorizações com o modelo formativo crítico para a docência, considerando a categoria de práxis para a aprendizagem e o desenvolvimento de educadores. Para tanto, discutimos os modelos de formação docente técnico, prático e crítico, nos atentando para o terceiro paradigma. Ao considerarmos este último modelo, articulamos seus princípios ao conceito de práxis de Paulo Freire e suas implicações na formação de educadores comprometidos com a transformação social. Ao final, avivamos as proposições de Freire e a sua urgente reflexão em um contexto de agravamento político e social, potencializado pela pandemia e pela necropolítica conservadora.
\end{abstract}

Palavras-Chave: Formação Docente. Modelos Formativos. Paulo Freire.

\begin{abstract}
In this essay we carried out a bibliographic research in order to analyze and understand the contributions of Paulo Freire to the field of research in teacher education, reflecting on the interfaces of his theorizations with the critical formative model for teaching, considering the category of praxis for the learning and development of educators. To this end, we discussed the technical, practical and critical teacher training models, paying attention to the third paradigm. When considering the latter model, we articulate its principles to Paulo Freire's concept of praxis and its implications for the formation of educators committed to social transformation. In the end, we enliven Freire's propositions and his urgent reflection in a context of political and social aggravation, enhanced by the pandemic and conservative necropolitics.
\end{abstract}

Keywords: Teacher Education. Formative Models. Paulo Freire.

\footnotetext{
1 Mestre em Educação e licenciado em História, ambos pela Universidade Federal de Viçosa. Email: derossi.caio@gmail.com.

${ }^{2}$ Licenciada em Pedagogia pela Universidade do Estado de Santa Catarina. Mestre e doutora em Educação Científica e Tecnológica pela Universidade Federal de Santa Catarina. Mestre em Educação pela Université de Nantes (França). Professora Adjunta do Departamento de Educação e do Programa de Pós-Graduação em Educação da Universidade Federal de Viçosa.E-mail: bmgeremias@ufv.br.
} 


\section{Palavras Iniciais}

Uma série de pesquisadores apontam para a historicidade e para a consolidação das investigações do campo de formação de professores, evidenciando a necessária atualidade de seus debates, bem como a longevidade das pesquisas (CELANI, 1988; NÓVOA, 1995; CANDAU, 2007; IMBERNÓN, 2010).

Conforme esses autores, é a partir dos anos finais da década de 1970 que os debates acerca da formação docente se intensificam, gerando uma série de investigações sobre as políticas públicas educacionais e problematizações acerca da inserção cada vez mais acentuada de grupos empresariais e neoliberais, que almejam empreender reformas na área. Embora suas razões e as motivações sejam distintas, tornando as do segundo grupo um tanto perniciosas, parece não haver discordâncias quanto à necessidade de reformulação na formação de educadores e nos sistemas educativos.

Sobre esta última observação, torna-se fundamental resgatar a crítica de Paulo Freire (1993b, p. 20) ao que ele denominou de "pacoteiros, sabichões e sabichonas" da administração, que de seus gabinetes e dotados de uma postura autoritária tentam desacreditar as escolas públicas e seus professores e professoras, propondo sempre mudanças - geralmente importadas de outras realidades e culturas - como se estes não tivessem conhecimentos e saberes suficientes para analisarem criticamente suas práticas e criarem coletivamente e de modo autônomo novas formas de ensinar, mais audazes e criativas.

Portanto, há questões de fundo que precisam ser sempre verbalizadas, para que mantenhamos nossos olhos vigilantes para as promessas que nascem de setores, cujo fim maior é a ampliação de seus nichos mercadológicos. Destacamos a pergunta formulada por Freire (1993b, p. 18) ao mencionar o papel das Políticas Públicas direcionadas à educação: “Como esperar [...] de uma administração de manifesta opção elitista, autoritária, que considere, na sua política educacional, a autonomia das escolas? Em nome da chamada pós-modernidade liberal?".

Acrescentamos a esta questão outras que se fazem pertinentes: De que modo os pesquisadores da educação, enquanto categoria, podem resistir aos modelos antidemocráticos e tecnocráticos de certas administrações cada vez mais atrelado à iniciativa privada, conivente com o processo de desmantelamento estrutural, econômico e ideológico da Educação nos tempos atuais e que suprime cada vez mais a autonomia das escolas e universidades? Que agenciamentos são estes que colocam sociedade contra a educação e contra seus professores, introduzindo reformas verticalizadas a cada dia mais nefastas e fazendo repercutir o discurso de que somos incapazes de gerir nosso próprio campo de atuação e de pesquisa?

Cumpre destacar que a ideia de campo de pesquisas sobre formação de professores é entendida sob a égide dos pressupostos de Bourdieu (2004), que 


\section{-Revista de Iniciação à Docência, v.6 , n. 2, 2021- \\ Publicação: dezembro, 2021 - ISSN 2525-4332}

compreende a categoria como um espaço autônomo, que produz e é resultante de formulações simbólicas, que correspondem a criações, a acordos e a ressignificações dos próprios participantes, que (con)formam os comportamentos e ações de seus integrantes. Nessa mesma perspectiva, pode-se entender o campo educacional dentro da heteronomia, já que para este autor a educação é menos autônoma, é menos forte, em relação a outros campos, como por exemplo, o da política, o da religião e o da economia.

Historicamente, observa-se a sobreposição de valores e interesses de campos mais fortes, mais autônomos, frente à área educacional. Portanto, isso enfatiza a importância de se pensar na luta educacional em torno de paradigmas formativos contra hegemônicos, refletindo sobre as rupturas e as permanências de interesses outros sobre o campo da educação.

Corroborando esses debates, Estrela (2006) destaca que o campo da formação de professores, para além de dimensões mais perceptíveis de análises e de agências - como dos pesquisadores que se debruçam sobre os aspectos formativos e/ou dos poderes legislativo e executivo que elaboram parâmetros, diretrizes e currículos - existem duas faces à penumbra: a da comunidade escolar e a dos interesses empresariais sobre a educação.

Apesar de uma série de investigações e investimentos paulatinos e crescentes sobre as temáticas, faz-se necessário compreender que a formação de professores passa também pela articulação com a comunidade, com os sindicatos e associações, e os demais movimentos de luta por melhores condições de trabalho. Da mesma forma, a formação docente precisa ser entendida à ribalta e como objeto de disputa de interesses econômicos, defendidos por grupos neoliberais e conservadores comprometidos com propostas de avaliação em larga escala e com a transformação da educação em seus diversos aspectos em mercadoria, tornando o desenvolvimento e a profissão dos profissionais da educação cada vez mais precária.

Destarte, visamos neste estudo refletir sobre as contribuições de Paulo Freire para o campo da formação docente, associando suas proposições ao paradigma formativo crítico e interpretando o seu conceito de práxis para o desenvolvimento e as aprendizagens dos professores.

Para tanto, realizamos os primeiros apontamentos sobre a formação docente e caracterizamos seus três modelos dominantes: o técnico, o prático e o crítico. Posteriormente, ao nos posicionarmos a favor do terceiro, discutimos as possíveis tessituras de seus princípios com os pressupostos freireanos, com ênfase nas implicações de sua compreensão de práxis para a formação docente e no seu compromisso com a transformação social.

Por fim, assinalamos a atualidade do pensamento freireano, especialmente em um contexto de agravamento dos quadros sociais pela pandemia e pela ingerência conservadora na contemporaneidade. 


\section{Modelos de formação docente: racionalidades em disputa}

De acordo com Diniz-Pereira (2011), existem distintos paradigmas que disputam a primazia para nortear as formações inicial e continuada dos professores. Para o autor, os principais modelos que fundamentam tais conhecimentos e interesses se referem aos paradigmas técnico, prático e crítico. Apresenta-se aqui uma visão sumarizada, sintética, já que as racionalidades serão retomadas em seção posterior.

Diniz-Pereira (2011), compreende como principais características do entendimento técnico o treinamento de habilidades, de comportamentos e de metodologias para que os docentes transmitam seus conhecimentos, uma vez que eles são vistos como técnicos, que devem aplicar os saberes pedagógicos e específicos de um campo disciplinar em prol de seus alunos.

Em se referindo ao paradigma da racionalidade prática, este autor destaca que o professor é convidado neste modelo a refletir sobre suas práticas, pensando as intencionalidades e as relações sociais existentes. Diferente do técnico, neste o processo de ensino-aprendizagem é observado além de um controle e reprodução de teorias e comportamentos, como eram as prerrogativas behaviorista e técnica, por exemplo.

Ainda em relação aos modelos de formação discutidos por Diniz-Pereira (2011), merece destaque o da racionalidade crítica, que propõe, de forma geral, que a práxis tenha o papel mobilizador de interpretação da realidade, assumindo o professor uma função de quem problematiza e constrói conhecimentos em conjunto com os interlocutores, tendo em vista a sua inserção social e almejando um mundo menos desigual.

É importante ressaltar que tais modelos se imiscuem entre si, não aparecendo uma única racionalidade como orientadora das práticas docentes. São as ações dos professores e os arranjos pedagógicos que propõem, oferecem materialidade e reconhecimento para refletir qual tipo de modelo orienta sua práxis.

Desse modo, são percebidos no passar do tempo e com maior ou menor adesão, uma série de teorias e práticas que nos convidam a refletir sobre caminhos distintos aos dos modelos hegemônicos, que se pautam pelas ideias do mercado e pela racionalidade técnica. Logo, a emergência de horizontes não-hegemônicos encontra como óbice o momento político-econômico que se estende pela atualidade, que pauta de forma desregulamentada as políticas públicas educacionais para a formação docente, sobrepondo os interesses econômicos, pragmáticos e individuais para a educação.

No mesmo sentido, Freitas (2014) assinala para a atuação de organismos internacionais como o Banco Mundial e o Banco Interamericano de Desenvolvimento, que agenciam em prol de interesses conservadores e econômicos, impactando as políticas públicas educacionais e a formação docente, quando forma um contingente de trabalhadores em função das demandas do mercado, reforçando toda gama de 


\section{-Revista de Iniciação à Docência, v.6 , n. 2, 2021- \\ Publicação: dezembro, 2021 - ISSN 2525-4332}

desigualdades. Cochran-Smith et al. (2009), acentuam que as mesmas instituições apregoam e reforçam discursos que atribuem as melhorias da educação e da formação docente para os países pobres e/ou em desenvolvimento a um maior grau de tecnicidade. Implica dizer, focalizam o debate na defesa de maior uso instrumental de tecnologias, no desenvolvimento de habilidades neste âmbito e no incentivo ao fortalecimento das empresas formadoras privadas. Cumpre ressaltar que os interesses hegemônicos, tais como o do capital, se apropriam e se transvestem com bandeiras das lutas sociais, em prol de seus interesses econômicos e sociais.

Tal modelo tecnicista, pretendente neutro e apolítico, dos tais pacoteiros educacionais (FREIRE, 1993b), ao se apropriarem dos discursos reformistas deslocam os papéis dos verdadeiros agentes educativos: professores, estudantes, comunidade escolar, criando ao mesmo tempo a ilusão de que basta introduzir novas técnicas e tecnologias, bem como metodologias para que a transformação educacional se efetive. Afinal, as administrações autoritárias, ao se tornarem clientes das grandes corporações educativas privadas, nada mais fazem do que fugir da democracia como o diabo da cruz" (FREIRE, 1993b, p. 25).

Assim, princípios como da justiça social, da democracia e da gestão participativa claramente de perfil contra hegemônico - são associadas com apoio da imprensa e de correntes negacionistas, ao ideário neoliberal, que reverbera pelo senso comum e por práticas governamentais.

Podemos exemplificar tal afirmação com dois acontecimentos recentes - embora reverberem de longo período histórico de sucessivos governos antidemocráticos e autoritários - que são os manifestos do movimento Escola sem partido e a contínua perseguição à Freire e sua obra, bem como aos que resistem revivendo e atualizando-o no mundo inteiro. Como efeito, vemos tomar mais força e forma a continuidade de uma pauta que transforma a educação em mercadoria, e que reendossa a divisão social do trabalho, ratificando as desigualdades e impossibilitando uma práxis transformadora, já que se efetivam as distâncias entre teoria e prática.

Com relação às políticas e as práticas que norteiam a formação docente, Imbernón (2010) infere que os processos formativos dos professores não impactam de forma linear e simultânea a qualidade da educação, embora alguns discursos paradoxais queiram fazer parecer. Nesse sentido, o autor (2010, p. 39) afirma que:

[...] há muita formação e pouca mudança. Talvez seja porque ainda predominam políticas e formadores que praticam com afinco e entusiasmo uma formação transmissora e uniforme, com predomínio de uma teoria descontextualizada, válida para todos sem diferenciação, distante dos problemas práticos e reais e fundamentada em um educador ideal que não existe.

Imbernón (2013, p. 51), ainda propõe que esse tipo de formação é orientado por "uma racionalidade técnica que buscava com afinco na pesquisa educativa ações generalizadoras para levá-las aos diversos contextos educativos”. Esse modelo, ao tentar 


\section{-Revista de Iniciação à Docência, v.6 , n. 2, 2021- \\ Publicação: dezembro, 2021 - ISSN 2525-4332}

garantir a universalidade dos currículos e práticas, travestidos novidade e modernidade, silenciam o fato de que "a educação é um evento histórico [...] que muda no tempo e no espaço", o que implica dizer que "é um engano [...] que uma nação, um estado, pense que se pode educar outras sociedades e outros povos [...]. A experiência não pode ser exportada, ela só pode ser reinventada" (FREIRE, 2016, p. 26-27).

Vaillant (2003) e Zeichner (2006), que trabalharam com as temáticas de políticas, práticas e formação de professores na América Latina e nos Estados Unidos respectivamente, endossam a crítica que os modelos hegemônicos orientados pelas perspectivas técnica e de mercado, não fomentam a transformação social nem a formação de uma sociedade mais equitativa. Isso, pois, no paradigma vigente, os discursos assinalam que a formação docente deve ser desconectada da realidade vivida e produzida ou por postular que a comunidade, os sujeitos e as instituições não influem nas dinâmicas dos trabalhos dos professores.

Produções como as de Serbino et al. (1998), Gatti e Barreto (2009), André (2010) e Gatti, Barreto e André (2011) sobre a formação docente brasileira, apontam que é a partir de 1990 que as práticas dos professores ganham destaque nas pesquisas do campo, uma vez que elas corroborariam com a compreensão dos desafios do trabalho e das próprias ações dos educadores, vislumbrando que não ocorressem retrocessos em uma dimensão da formação prática e/ou crítica, bem como das suas repercussões gerais pela educação básica, por exemplo.

Assim, autores como Giroux (1997), Freire (2001), Nóvoa (2009) e Zeichner (2011), vão ser alguns exemplos de teóricos, que entre outros, postulam a necessidade de pensar a formação docente para além dos modelos hegemônicos, focando o desenvolvimento da autonomia e da práxis crítica comprometida com a mudança social. Nesse sentido, destacamos parte do prefácio escrito por Giroux, na obra Pedagogia da Solidariedade (FREIRE; OLIVEIRA, 2016, p. 17-19) em que o autor chama a atenção para que mantenhamos a esperança na era do descartável, pois:

\footnotetext{
Para Freire a esperança é uma prática de testemunho, um ato de imaginação moral que encoraja educadores progressistas e outros a firmarem-se na margem da sociedade, de pensar para além das configurações de poder existentes para que se possa imaginar o impensável em termos de como viver com dignidade, justiça e liberdade. A esperança demanda ancorar-se em práticas transformativas e das tarefas do educador progressista [acrescentamos, de uma educação progressista] é "desvelar oportunidades para a esperança, sejam quais forem os obstáculos".
}

Tal "política da esperança", exige posições não doutrinárias, bem como uma pedagogia "que se auto localiza na linha divisória onde as relações de dominação e opressão, poder e falta de poder continuam a ser produzidas e reproduzidas. Entendendo que a primeira tarefa da política dominante é tornar o poder invisível" (FREIRE; OLIVEIRA, 2016, p. 19). No contexto atual, marcado pela pandemia do coronavírus, podemos 


\section{-Revista de Iniciação à Docência, v.6 , n. 2, 2021- \\ Publicação: dezembro, 2021 - ISSN 2525-4332}

constatar a materialidade desse poder no aumento da desigualdade e da indiferença frente aos milhões de brasileiros oprimidos pela doença e pela fome.

Pensadores como Giroux e Nóvoa demonstram a reconhecida contribuição de Freire para o cenário mundial, tanto pela constante atualização e ressignificação de sua obra no debate político, social, econômico e educacional na contemporaneidade, especialmente em um momento que se observa no Brasil um governo conservador, consolidado após o golpe político-midiático-jurídico de 2016 (MATTOS; BESSONE; MAMIGONIAN, 2016). Podemos dizer que, pretensamente, há uma série de deslocamentos, nos discursos conservadores, de categorias como ideologia e doutrinação, atribuindo tais compreensões aos escritos de Freire.

E por fim, uma política de governo que escancara a opção pela morte e pela barbárie, com a não gestão da crise pandêmica, em um momento que os dados registram quase seiscentas mil mortes desde o início da pandemia, no contexto de escrita e revisão do presente artigo, e marcas de quase quatro mil óbitos diários, em momentos de auge do quadro pandêmico. Portanto, as proposições de Freire nos convidam para pensar no futuro, que mesmo incerto e provável, seja marcado pela defesa democrática e pela justiça social. É também nesse sentido, que com base em Mbembe (2018) adota-se a ideia de necropolítica, que é quando o Estado dispõe como aceitável a morte de determinados grupos e/ou corpos, naturalizando a vulnerabilidade e a diferenciação das pessoas.

Destarte, o texto discutirá as propostas de Freire para a formação docente, considerando a miríade de aspectos envolvidos nas teorias, nas práticas e nas possíveis respostas para os desafios que se apresentam na formação e no trabalho. Para tanto, além das seções introdutória e de considerações finais, o presente texto apresenta as discussões da racionalidade crítica para a formação docente, os pressupostos da práxis de Freire, ancorados em um modelo contra hegemônico e no desenvolvimento formativo da docência para a justiça e a transformação social.

\section{A racionalidade crítica na formação de professores}

A presente seção propõe discutir de modo mais aprofundado as três racionalidades que pautam conscientemente ou não, as pesquisas e os modelos de formação docente no Brasil e no exterior: a técnica, a prática e a crítica, supracitados anteriormente. Para atingir ao objetivo deste estudo refletimos com maior ênfase acerca da perspectiva formativa crítica, em função de sua interface com as propostas de Freire.

O modelo da racionalidade técnica se baseia na epistemologia positivista que preconiza o papel do professor como um aplicador de técnicas, de teorias. Para Schon (1983), o docente nesse paradigma é entendido como um técnico, que coloca em prática os conhecimentos pedagógicos e específicos de um campo disciplinar na sala de aula. $O$ paradigma técnico é um dos mais consolidados no mundo, presente em distintos 


\section{-Revista de Iniciação à Docência, v.6 , n. 2, 2021- \\ Publicação: dezembro, 2021 - ISSN 2525-4332}

currículos, já que instituições como o Banco Mundial e o Banco Interamericano de Desenvolvimento, por exemplo, preconizam reformas conservadoras e de interesses do mercado no campo de formação docente (DE TOMASSI; WARDE; HADDAD, 1996).

No avançar das discussões, os pesquisadores percebem a necessidade do alinhamento de pressupostos considerados teóricos e práticos, bem como o reconhecimento que os professores, mesmo diante de incertezas, refletem sobre suas práticas educativas. Nesse sentido, propõe-se a racionalidade prática, que para Carr e Kemis (1986), não se reduz ao controle de aplicações de técnicas para a aprendizagem, mas sim, marca um processo de aprendizagem profissional com base na avaliação das próprias experiências, ações como docente. Logo, o pressuposto da prática é antagônico ao espectro positivista, buscando então, romper com uma lógica tradicional vigente.

Entretanto, os próprios Carr e Kemis (1986) e Elliot (1991) já indicam que instituições econômicas internacionais e conservadoras já se apropriaram da categoria de racionalidade prática, como forma de adequação aos processos educativos estarem mais próximos aos interesses do mercado, como a formação de mão de obra barata e não especializada.

Perante o quadro, Carr e Kemis (1986) concebem que, com base em uma releitura das teorias da Escola de Frankfurt, principalmente das ideias da ciência sócio crítica do filósofo Jurgen Habermas, as visões técnica e prática acabam por se assemelhar, já que ambas pretendem alcançar objetivos educacionais complexos de forma restrita: ora pelo enfoque em um conjunto de habilidades e comportamentos, ora pela autonomia e deliberações profissionais. Desse modo, Carr e Kemis (1986, p. 183) afirmam que:

\footnotetext{
Enquanto os pesquisadores positivistas da educação podem frequentemente ser descritos como "objetivistas", enfatizando a natureza objetiva do conhecimento como independente do observador, e pesquisadores interpretativistas da educação podem ser descritos como "subjetivistas", enfatizando a compreensão subjetiva do ator como base para a interpretação da realidade social, pesquisadores críticos da educação, incluindo aqueles que atuam na pesquisa-ação, adotam uma visão de racionalidade dialética. Portanto, [...] tais pesquisadores tentam descobrir como situações são forjadas por condições "objetivas" e "subjetivas" e procuram explorar como tais tipos de condições podem ser transformadas.
}

Logo, os autores (1986) compreendem que não são os paradigmas técnico e prático capazes de transformar a ordem social. Da mesma forma, os pesquisadores apontam que a perspectiva dicotômica de teoria e prática, por sua vez, também não são capazes de pensar a alteração da ordem social vigente. Nesse sentido, é a visão crítica, comprometida com a mudança da sociedade e da educação, que se configura como um horizonte a ser seguido.

Carr e Kemis (1986) afirmam que a racionalidade crítica precisa ser compreendida dentro dos seus aspectos sócio históricos, já que a formação deve ser compreendida 


\title{
-Revista de Iniciação à Docência, v.6 , n. 2, 2021- Publicação: dezembro, 2021 - ISSN 2525-4332
}

como uma atividade social, política e problemática, uma vez que possuem relações, consequências e implicações sociais com os demais sujeitos, com o tempo e com o meio. Nas palavras dos autores (1986, p. 156):

\begin{abstract}
Ela [racionalidade crítica] carrega uma visão de pesquisa educacional como análise crítica que direciona a transformação da prática educacional, os entendimentos sobre educação, e os valores educacionais daqueles envolvidos no processo, e as estruturas sociais e institucionais as quais fornecem o esqueleto para sua ação. Nesse sentido, uma ciência da educação crítica não é uma pesquisa sobre ou a respeito de educação, ela é uma pesquisa na e para a educação.
\end{abstract}

Dessa forma, Carr e Kemis (1986) analisam os professores na perspectiva crítica como pesquisadores de suas práticas pedagógicas e dos currículos, uma vez que adotam uma postura de problematização diante de suas próprias experiências, desenvolvimentos e aprendizagens. Para esses autores (1986, p. 40) são os professores que:

[...] ajudam a estabelecer comunidades críticas de pesquisa no ensino, no currículo e na organização da escola, e administração de grupos dentro da escola, da escola como um todo ou entre escolas. Essa auto-reflexão crítica, empreendida em uma comunidade auto-crítica, usa comunicação como um meio para desenvolver um sentido de experiência comparada, para descobrir determinantes locais ou imediatos sobre a ação pela compreensão dos contextos dentro dos quais outros trabalham e convertendo experiência em discurso, usando a linguagem como auxílio para a análise e o desenvolvimento de um vocabulário crítico o qual fornece os termos para a reconstrução prática.

A racionalidade crítica entende o professor como um mediador e propositor de questões, não circunscritas ao campo disciplinar que atua, como também dispunham os paradigmas técnico e prático, mas como, quem levanta problemas sobre o trabalho e suas práticas, ressaltando a perspectiva intrinsecamente política da formação crítica.

Para Shor (1992), a proposição de dúvidas e de questões encontrou lugar profícuo e de destaque nas teorias acerca da experiência e da democracia do filósofo norteamericano John Dewey e da epistemologia genética do biólogo e psicólogo suíço Jean Piaget. Porém, foi Freire com a disposição de uma metodologia da problematização, que explicitou o compromisso político da educação e do educador, propondo, a partir do levantamento de questões, um diálogo crítico com os interlocutores. Fazer perguntas para Freire, é desenvolver uma pedagogia. Nesse sentido, Shor (1992, p. 31) advoga que:

Como pedagogia e filosofia social, o levantamento de problemas enfatiza relações de poder em sala de aula, na instituição, na formação de critérios padronizados de conhecimento e na sociedade como um todo. Ela considera o contexto social e cultural da educação, perguntando como a subjetividade do estudante e suas condições econômicas afetam o processo de aprendizagem. A cultura do estudante bem como a desigualdade e a democracia são temas centrais para educadores "levantadores de problemas" quando eles examinam cuidadosamente o ambiente para a aprendizagem.

Para Freire, o levantamento de questões serve para que tantos alunos como professores problematizem as naturezas de suas aprendizagens, as relações de poder presentes e os contextos temporais e espaciais em que tais interações são produzidas. 


\section{-Revista de Iniciação à Docência, v.6 , n. 2, 2021- \\ Publicação: dezembro, 2021 - ISSN 2525-4332}

Portanto, retorna-se a ideia de que os docentes e discentes são pesquisadores de suas práticas e dos currículos, com o objetivo de propor uma construção epistemológica democrática.

Alguns autores vão propor uma subdivisão de modelos formativos baseados no paradigma da racionalidade crítica. Liston e Zeichner (1991), defendem a visão sócio reconstrutivista, que entende a educação como meio da promoção da igualdade e da justiça social. Hooks (2013), concebe a educação de forma aliada ao ativismo e a militância políticas, refletindo no modelo emancipatório e/ou transgressivo, caminhos para o professor subverter ordens tradicionais vigentes, abrindo possibilidades para a construção de novos itinerários formativos. Para Carson e Sumara (1997), a formação docente deve ser tratada a partir de uma lógica da pesquisa-ação que propõe no paradigma ecológico crítico, a possibilidade de romper e propor uma outra sociedade, menos desigual, e portanto, transformada.

Como vimos, as três racionalidades aqui debatidas apontam para uma multiplicidade de modos de se propor e de se analisar a formação docente, demonstrando deslocamentos de discursos e práticas que precisam ser considerados ao optarmos ou defendermos determinadas perspectivas.

Ao nos filiarmos às perspectivas críticas de formação docente, enfocamos a discussão nas contribuições de Freire, como pensador brasileiro e latino-americano reconhecido mundialmente, pois concordamos com ele quando este não cessa de dizer que "a experiência não pode ser exportada" (2016, p. 27)" e que "a educação não pode ser somente técnica [...] tem que ser política" (p. 38).

Tendo em vista essas compreensões, discutimos posteriormente as ideias freireanas sobre formação de professores, partindo da problematização e do sentido da necessidade da práxis.

\section{A práxis de freire e a formação docente: um modelo contra hegemônico}

Nesta seção, apresentamos algumas sinalizações acerca da perspectiva de práxis em Freire para os processos formativos dos professores. Em função da sua trajetória, práticas e interlocutores tão diversos, a questão da formação docente em Paulo Freire se apresenta de modo distinto e holístico.

A categoria da práxis, desenvolvida na obra Pedagogia do Oprimido, situa a educação como uma das formas de "ação e reflexão dos homens sobre o mundo para transformá-lo" (FREIRE, 2013, p. 52). Conforme Carvalho e Pio (2017, p. 432), os sentidos sobre a práxis recebem em Freire conotações diversas: “ora evoca a categoria da práxis de forma isolada, ora a utiliza de forma adjetivada: práxis libertadora, práxis autêntica, práxis revolucionária e práxis verdadeira”. Em defesa de uma educação problematizadora, o educador preconiza a libertação dos mecanismos de opressão, 


\section{-Revista de Iniciação à Docência, v.6 , n. 2, 2021- Publicação: dezembro, 2021 - ISSN 2525-4332}

sobretudo em países colonizados, como finalidade da ação e reflexão sobre a realidade concreta e historicamente produzida e situada (FREITAS; FORSTER, 2016).

Freire alinhava as questões sobre formação docente, com base nos princípios da democracia, do diálogo, da construção epistemológica e da práxis, evidenciados por uma escrita acessível e que enfoca a dimensão política da educação. Assim, realiza uma proposta que possui dimensões antropológicas, sociopolíticas e filosóficas sobre o saber fazer docente, que legaram nas décadas de 1980 e 1990 contributos para a reflexão das práticas, do processo de ensino-aprendizagem e da formação de educadores.

Tendo em vista a vasta produção do autor, algumas obras, entre tantas outras que poderiam ser citadas, elaboram sobre a docência e suas dinâmicas formativas, sendo destacadas aqui: Pedagogia da autonomia: saberes necessários à prática (1996), Educação na cidade (2001), Política e Educação (1993a), Professora sim, tia não: cartas a quem ousa ensinar (1993b) e Medo e ousadia: o cotidiano do professor (1987), esse último escrito em conjunto com o professor Ira Shor.

Paulo Freire ofereceu destaque para pensar a formação docente de modo continuado, permanente, reconhecendo que o desenvolvimento profissional e a aprendizagem da docência se dão ao longo de toda vida. Nesse sentido, o autor (2001, p. 80) afirma que:

[...] um dos programas prioritários em que estou profundamente empenhado é o de formação permanente dos educadores, por entender que os educadores necessitam de uma prática político-pedagógica séria e competente que responda à nova fisionomia da escola que se busca construir.

A proposição da formação permanente para Freire implica a consciência do seu inacabamento, constituindo o professor como um ser igualmente inacabado, $\mathrm{O}$ inacabamento ou o movimento do vir-a-ser é marca de nossa humanidade, nos impelindo a buscar e a construir novos conhecimentos.

Nesse sentido, o exercício epistemológico é uma característica ontológica do ser humano, que evidencia o protagonismo dos sujeitos na escrita da história, bem como o comprometimento e a insatisfação perante as desigualdades, que oprimem e retiram a humanidade das pessoas. Conforme o autor (1993, p. 22-23):

A educação é permanente não porque certa linha ideológica ou certa posição política ou certo interesse econômico o exijam. A educação é permanente na razão, de um lado, da finitude do ser humano, de outro, da consciência que ele tem de sua finitude. Mais ainda, pelo fato de, ao longo da história, ter incorporado à sua natureza não apenas saber que vivia, mas saber que sabia e, assim, saber que podia saber mais. A educação e a formação permanente se fundam aí.

Freire marca a posição de uma formação que deve contemplar a reflexão na/sobre a ação, priorizando as práticas cotidianas e propondo uma práxis que relacione os aspectos teórico-epistemológico da profissão com a vida e o trabalho dos professores. 


\section{-Revista de Iniciação à Docência, v.6 , n. 2, 2021- \\ Publicação: dezembro, 2021 - ISSN 2525-4332}

A junção entre teoria e prática fomenta a consciência crítica, na direção que reconhece a escola como espaço de formação e de aprendizagem, bem como a partilha de experiências dos pares, faz com que se reflita e se repense a própria formação, as próprias práticas. O trabalho coletivo e o diálogo são as principais marcas das proposições de Freire, primando a construção de conhecimento de modo democrático, integrando a escola e a universidade como parceiras na formação e o estabelecimento escolar como lócus do processo de desenvolvimento continuado.

Cumpre destacar que Paulo Freire assumiu a responsabilidade pela gestão das políticas públicas educacionais na gestão da prefeita Luiza Erundina, na época filiada ao Partido dos Trabalhadores, entre os anos de 1989-1992. Freire, respondendo às demandas do secretário de Educação Mário Sérgio Cortella, cuidava da organização dos cursos de formação permanente para os docentes da rede municipal paulista. Nesse período citado, o educador pernambucano coordenou uma série de Cadernos de Formação, utilizados pelos grupos de professores, bem como os Núcleos de Ação Educativa (NAEs) e a Diretoria de Orientação Técnica (DOT) (SAUL; SAUL, 2016).

Ressaltamos as experiências de Freire nos âmbitos ensino, pesquisa, extensão e gestão, em várias instituições e contextos no Brasil e em outros países. Entretanto, o exemplo da experiência na Secretaria Municipal de Educação de São Paulo, além de oferecer uma ilustração da práxis formativa para os docentes, teve, como todos os seus demais projetos, reconhecimento e repercussão prática na vida e na formação dos sujeitos. Nas palavras de Gatti e Barreto (2009, p. 202):

\footnotetext{
O Projeto Grupos de Formação desenvolvido pela Secretaria Municipal de São Paulo, entre 1989 e 1992, atingiu todas as escolas e adotou uma dinâmica de formação continuada que favoreceu o protagonismo do professor e da escola. $\mathrm{O}$ fator favorável à implementação do projeto foi a criação de um estatuto do magistério que previa 40 horas de trabalho semanais, sendo 20 em sala de aula e 20 dedicados a estudos, planejamentos, formação, remunerados. Estudos sobre processos de formação continuada com perfil semelhante, realizados em sistemas municipais, revelam seu alto potencial para induzir modificações significativas na educação local, mas seus efeitos positivos podem ser limitados em decorrência de situações de alternância de poder e mudanças programáticas de governo.
}

Portanto, as autoras (2009) apontam que as propostas de Freire realizadas no âmbito do município de São Paulo influenciaram outros programas de formação. $O$ componente político e a relação com os movimentos sociais, marcam a postura progressista e a relevância da formação dos profissionais da educação em serviço, de modo contínuo. 


\section{A formação docente a justiça e a transformação social}

A presente seção faz um apanhado conceitual das categorias justiça social e transformação social, sinalizando pontos de toque e de afastamento aos pressupostos teóricos para a formação docente em Freire.

Zeichner (2004) em um extenso levantamento e análise das produções especializadas norte-americanas, identifica que em mais de sete décadas, uma série de programas voltados para a formação docente, denominam em seus currículos que se ancoram em pressupostos da justiça social para o desenvolvimento de professores. Para ele, desde a década 1980, com a emergência dos pressupostos da reflexão para a formação de educadores, se tornou recorrente a ligação entre os elementos formativos e a justiça social, mesmo ainda que de forma indefinida. Mesmo admitindo que os termos podem evocar sentidos amplos e diferentes correspondentes, e que a literatura não possui um consenso para a discussão, é ponto pacífico, afirma o autor, que se analise quais sentidos de justiça social estão sendo preconizados.

Por isso, Zeichner (2004) evidencia que a reflexão acerca da formação docente e da justiça social são necessárias, uma vez que são percebidas, por vezes, incongruências, entre os discursos e as práticas de tais programas formativos, no contexto norteamericano.

Uma questão central para esse debate, quando nos referimos à Freire, é a categoria justiça social historicamente utilizada por grupos, organizações e sindicatos populares, progressistas, comprometidos com a transformação da realidade social, tal qual pregou a pedagogia freireana. Entretanto, a luta pela igualdade, por condições pareadas a todos, sem distinções, é cada vez mais apropriada pelos interesses neoliberais e conservadores, que se utilizam do termo justiça social para pregar sobre a pretensa liberdade de consumo e competição na sociedade capitalista, baseada na falácia da meritocracia. Portanto, a justiça social para os grupos conservadores se relaciona com as demandas das grandes empresas para a formação de mão de obra, para o consumo e para uma sedução discursiva do êxito econômico, que desconsidera as realidades objetivas das desigualdades.

O que se propõe aqui é que a justiça social é uma posição política antagônica aos princípios conservadores e neoliberais, justamente por questionar o status quo das desigualdades, marcando uma postura combativa em prol do desenvolvimento mais justo da sociedade. Assumir uma posição contrária à ordem vigente, assinala para a oposição ao capitalismo, as ideias imperialistas, ao patriarcado, ao racismo, a aporofobia3, a homofobia, ao capacitismo e a todo tipo de violência e barbárie.

\footnotetext{
${ }^{3}$ Relativo a uma postura hostil, de repulsa a sujeitos pobres, menos favorecidos socioeconomicamente e/ou em condição de miséria.
} 


\section{-Revista de Iniciação à Docência, v.6 , n. 2, 2021- \\ Publicação: dezembro, 2021 - ISSN 2525-4332}

Por mais que a categoria justiça social seja explicada em seus significados preconizados e encontre correspondente nas ideias de Freire, em acordo com DinizPereira e Soares (2019), utilizar-se-á a ênfase na ideia de transformação social na obra freireana. Cumpre destacar que não se trata de uma relação de antinomia entre justiça e transformação social, mas que o segundo termo é mais representativo do caráter intrinsecamente político da educação. Da mesma forma que o termo justiça social é problemático por ser apropriado pelos interesses do capital, o conceito de inclusão social dos educadores, tema recorrente no contexto brasileiro, também pode se revelar problemático, em razão das desigualdades e dos interesses hegemônicos do capital.

Logo, o entendimento chancelado aqui é o de pensar as ideias de Freire a partir do entendimento de transformação social, marcando uma posição contrária ao avanço reacionário conservador, bem como sinalizando para o reconhecimento dos processos violentos e históricos que apagam as diferenças, transformando-as em desigualdades (DINIZ-PEREIRA; LEÃO, 2008).

A base da sociedade capitalista, que se assenta em todas as desigualdades e violências supracitadas, têm a exclusão e os antagonismos de classe como marcas idiossincráticas principais, encontrando na justiça e/ou na inclusão social, um percurso discursivo assumido pelas elites políticas e econômicos como um horizonte que será seguido, mas nunca efetivado. Por isso, fazendo alusão aos grupos de camada popular, trabalhadores analfabetos e demais segmentos marginalizados, que foram parceiros de interlocução e aprendizagens para Freire, a transformação social, encontra nas lutas e nos anseios de tais trabalhadores, agência e destino sociais e coletivos para uma vida melhor e para a liberdade. Esta última compreendida como "é uma conquista, e não uma doação, exige uma permanente busca” (FREIRE, 1987, p. 68).

Portanto, reiteramos a imprescindibilidade de uma formação com e não para os professores, bem como um espaço formativo que articule educação e sociedade, em prol da restituição do reconhecimento de dignidade e de humanidade para aqueles considerados aquém dos direitos básicos, essenciais.

Destarte, por mais que no horizonte se aprumem os desafios e os limites dos processos formativos, dos seus sujeitos e das suas instituições, em um contexto de desigualdades próprias do capital, o texto aponta alguns indícios de possibilidades, mesmo sem respostas formuladas, são deixadas para a reflexão e para a práxis coletivas educacionais e de formação de professores.

\section{Considerações Finais}

O presente artigo buscou refletir sobre os aspectos concernentes aos modelos de formação de professores, buscando uma aproximação da temática com as proposições freireanas. Ao apresentarmos os paradigmas que norteiam a formação docente 


\section{-Revista de Iniciação à Docência, v.6 , n. 2, 2021- \\ Publicação: dezembro, 2021 - ISSN 2525-4332}

enfatizamos o modelo crítico, na direção da proximidade com os ideais defendidos por Freire, aos quais nos filiamos. A discussão sobre os elementos da práxis freireana e suas interseções com os processos e as dinâmicas formativas dos professores. Ao fim, debateu-se a interlocução dos conceitos de justiça e de transformação sociais, em seus termos teórico-metodológicos e seus pontos de toque e de afastamento com as proposições de Freire.

A problematização proposta como pilar do sentido formativo em Freire, possibilita recriar, reinventar e materializar outras práticas, outras teorias, uma vez que os conceitos e as categorias postos advêm das realidades construídas, relacionais e políticas dos sujeitos e dos contextos.

Consideramos que os princípios educativos e formativos discutidos nas obras aqui abordadas nos fornecem subsídios para uma atualização e recriação nas pesquisas e nas práticas de formação docente que considerem os aspectos concretos do tempo, do espaço e dos sujeitos, evidenciando assim, a atualidade de sua obra. Portanto, é com a visão da pesquisa, entendida como prática de problematização das ações e dos currículos, e com a postura de comprometimento com os aspectos sociais, que se pode efetivar a formação permanente proposta por Freire, baseada em uma mirada crítica das realidades educacional e social.

Nessa direção, a formação docente proposta por Freire, além de considerar aspectos éticos, políticos e das práticas profissionais, evoca a relevância da crítica, como marca da humanidade frente ao compromisso de construir um mundo melhor para todos. Logo, fundamentados em um horizonte de possibilidades calcadas na recriação e na práxis social construída coletivamente, reafirmamos a sempre necessária postura de enfrentamento das desigualdades, das injustiças, das violências e da pretensa ideia de neutralidade.

Por conseguinte, encerramos esse estudo de caráter bibliográfico, convidando as instâncias formativas e os/as docentes a buscarem caminhos alternativos na e para a formação de educadores. Caminhos estes que sejam igualmente compreendidos como atos de resistência, sobretudo nesse momento de constante perseguição à Freire e à educação nacional, acrescida de desinvestimento público.

\section{Referências}

ANDRÉ, Marli Elisa Dalmazo de Afonso. Formação de professores: a constituição de um campo de estudos. Educação, Porto Alegre, v. 33, p. 6-18, 2010.

BOURDIEU, Pierre. Os usos sociais da ciência: por uma sociologia clínica do campo científico. São Paulo: Editora da UNESP, 2004.

CANDAU, Vera Maria. Formação continuada de professores: tendências atuais. In: REALI, Aline Maria de Medeiros; MIZUKAMI, Maria da Graça Nicoletti (Org.). Formação de professores: tendências atuais. São Carlos: EdUSFCar, 2007. p. 139-152. 
CARR, Wilfred; KEMMIS, Stephen. Becoming critical: education, knowledge and action research. London: The Falmer Press, 1986.

CARVALHO, Sandra Maria Gadelha de; PIO, Paulo Martins. A categoria da práxis em Pedagogia do Oprimido: sentidos e implicações para a educação libertadora. Rev. Bras. Estud. Pedagog. Brasília, v. 98, n. 249, 2017, p. 428-445. Disponível em: http://www.scielo.br/scielo.php?script=sci_arttext\&pid=S217666812017000200428\&lng=en\&nrm=iso. Acesso em: abril de 2021.

CARSON, Terrance; SUMARA, Dennis. (Org.). Action research as a living practice. New York: Peter Lang, 1997.

CELANI, Maria Antonieta Alba. A educação continuada do professor. SBPC Ciência e Cultura, São Paulo, v. 40, n. 2, p. 158-163, fev. 1998.

COCHRAN-SMITH, Marilyn; FURLONG, John; BRENNAN, Marie. (Ed.). Policy and Politics in Teacher Education: International Perspectives. London: Routledge Taylor \& Francis, 2009.

DINIZ-PEREIRA, Júlio Emílio. A pesquisa dos educadores como estratégia para construção de modelos críticos de formação docente. In: ZEICHNER, Kenneth; DINIZ-PEREIRA, Júlio Emílio. (Org.). A pesquisa na formação e no trabalho docente. Belo Horizonte: Editora Autêntica, 2011. p. 11-38.

DINIZ-PEREIRA, Júlio Emílio; LEÃO, Geraldo. (Org.). Quando a diversidade interroga a formação docente. Belo Horizonte: Autêntica, 2008.

DINIZ-PEREIRA, Júlio Emílio; SOARES, Leôncio José Gomes. Formação de educadoras/es, diversidade e compromisso social. Educação em Revista, Belo Horizonte, v. 35, n. 21, p. 123, 2019.

DE TOMMASI, Livia; WARDE, Miriam; HADDAD, Sérgio. (Org.). O Banco Mundial e as políticas educacionais. São Paulo: Cortez Editora, 1996.

ELLIOT, John. Action Research for Educational Change. Buckingham: Open University Press, 1991.

ESTRELA, Maria Teresa. A formação contínua entre a teoria e a prática. In: FERREIRA, N. S. C. (Org.). Formação continuada e gestão da educação. São Paulo: Cortez, 2006. p. 4364 .

FREIRE, Paulo; SHOR, Ira. Medo e ousadia: o cotidiano do professor. São Paulo: Paz e Terra, 1987.

FREIRE, Paulo; FREIRE, Ana; OLIVEIRA, Walter. Pedagogia da solidariedade. $2^{\mathrm{a}}$ Ed. Rio de Janeiro/São Paulo: paz e terra, 2016.

FREIRE, Paulo. Pedagogia do oprimido. 54. ed. Rio de Janeiro: Paz e Terra, 2013.

FREIRE, Paulo. Política e educação. Indaiatuba: Villa das Letras Editora, 1993 .

FREIRE, Paulo. Professora sim, tia não: cartas a quem ousa ensinar. São Paulo: Paz e Terra, $1993 \mathrm{~b}$.

FREIRE, Paulo. Pedagogia da autonomia: saberes necessários à prática educativa. São Paulo: Editora Paz e Terra, 1996.

FREIRE, Paulo. A educação na cidade. São Paulo: Editora Cortez, 2001. 
FREITAS, Luís Carlos de. Os empresários e a política educacional: como o proclamado direito à educação de qualidade é negado na prática pelos reformadores empresariais. Germinal: Marxismo e Educação em Debate, Salvador, v. 6, n. 1, p. 48-59, jun. 2014. Disponível em: <http://www.portalseer.ufba.br/index.php/revistagerminal/article/view/12594/8857>. Acesso em: março de 2021.

FREITAS, Ana Lúcia Souza de; FORSTER, Maria Margarete dos Santos. Paulo Freire na formação de educadores: contribuições para o desenvolvimento de práticas críticoreflexivas. Educar em Revista, Curitiba, Brasil, n. 61, p. 55-69, jul./set. 2016.

GATTI, Bernadete Angelina; BARRETO, Elba Siqueira de Sá. (Coord.). Professores do Brasil: impasses e desafios. Brasília: UNESCO, 2009.

GATTI, Bernadete Angelina; BARRETO, Elba Siqueira de Sá; ANDRÉ, Marli Elisa Dalmazo de Afonso. Políticas docentes no Brasil: um estado da arte. Brasília: UNESCO, 2011.

GIROUX, Henry. Os professores como intelectuais: rumo a uma pedagogia crítica da aprendizagem. Porto Alegre: Artmed, 1997.

HOOKS, Bell. Ensinando a transgredir: a educação como prática de liberdade. Tradução de Marcelo Brandão Cipolla. São Paulo: Martins Fontes, 2013.

IMBERNÓN, Francisco. Formação continuada de professores. Porto Alegre: Artmed, 2010. IMBERNÓN, Francisco. Formação permanente do professorado: novas tendências. São Paulo: Cortez, 2013.

LISTON, Daniel; ZEICHNER, Kenneth. Teacher Education and the Social Conditions of Schooling. New York: Routledge, 1991.

MARCELO, Carlos. Formação de professores: para uma mudança educativa. Porto: Porto Editora, 2013.

MATTOS, Hebe; BESSONE, Tânia; MAMIGONIAN, Beatriz. Historiadores pela democracia. O golpe de 2016: a força do passado. São Paulo: Alameda Editorial, 2016.

MBEMBE, Achille. Necropolítica. 3. ed. São Paulo: n-1 edições, 2018.

NÓVOA, Antonio. (Coord.). Os professores e a sua formação. Lisboa: Publicações Dom Quixote, 1995.

NÓVOA, Antonio. Notas sobre um regresso adiado. Educação, sociedade e culturas, Porto, n. 10, p. 155-174, 1998. Disponível em:

<http://www.fpce.up.pt/ciie/revistaesc/ESC10/10-dialogos.pdf>. Acesso em: abril de 2021. NÓVOA, Antonio. Professores: imagens do futuro presente. Lisboa: Educa, 2009.

SAUL, Ana Maria; SAUL, Alexandre. Contribuições de Paulo Freire para a formação de educadores: fundamentos e práticas de um paradigma contra-hegemônico. Educar em Revista, Curitiba, n. 61, p. 19-35, jul./set. 2016.

SCHÖN, Donald. The reflective practitioner. New York: Basic Books, 1983.

SERBINO, Raquel Volpato; RIBEIRO, Ricardo; BARBOSA, Raquel Lazzari Leite; GEBRAN, Raimunda Abou (Org.). Formação de professores. São Paulo: Editora UNESP, 1998.

SHOR, Ira. Critical teaching and everyday life. Chicago: University of Chicago Press, 1992. 
VAILLANT, Denise. Formação de Formadores: estado da prática. [S. I.]: PREAL, 2003. Disponível em:

http://www.oei.es/docentes/articulos/formacion_formadores_estado_practica_vaillant_p ortugues.pdf. Acesso em: março de 2021.

ZEICHNER, Kenneth. Different conceptions of teacher expertise and teacher education in the USA. Education Research and perspectives, Crawley, v. 33, n. 2, p. 60-79, 2006.

ZEICHNER, Kenneth. A pesquisa-ação e a formação docente voltada para a justiça social: um estudo de caso dos Estados Unidos. In: ZEICHNER, Kenneth; DINIZ-PEREIRA, Júlio Emílio (Org.). A pesquisa na formação e no trabalho docente. Belo Horizonte: Editora Autêntica, 2011. p. 61-84.

Recebido: 22.07.2021

Aprovado: 01.11.2021 